\title{
Surgical versus nonsurgical interventions to relieve upper airway obstruction in children with Pierre Robin sequence
}

\author{
Karen Kam MD FRCPC ${ }^{1}$, Meghan McKay BA ${ }^{2}$, Joanna MacLean MD PhD FRCPC ${ }^{3}$, Manisha B Witmans MD FRCPC ${ }^{3}$,
} Sheldon Spier MD FRCPC ${ }^{2}$, Ian Mitchell MB MA FRCPC ${ }^{1}$

\begin{abstract}
K Kam, M McKay, J MacLean, MB Witmans, S Spier, I Mitchell. Surgical versus nonsurgical interventions to relieve upper airway obstruction in children with Pierre Robin sequence. Can Respir J 2015;22(3):171-175.
\end{abstract}

BACKGROUND: Newborns with Pierre Robin sequence (PRS) often experience chronic intermittent hypoxemia/hypoventilation associated with airway obstruction. The heterogeneity of the severity of upper airway obstruction makes management a challenge; the optimal intervention in individual cases is not clear.

OBJECTIVE: To investigate the prevalence of surgical/nonsurgical interventions for PRS at two children's hospitals. Patient characteristics and outcomes were examined.

METHODS: The present retrospective chart review identified 139 patients with PRS born between 2000 and 2010. Demographic information, mode of airway management, associated anomalies and syndromes, polysomnography results, length of intensive care unit and hospital stay, complications and deaths were extracted.

RESULTS: Interventions included prone positioning (alone [61\%]), tongue-lip adhesion (45\%), nasopharyngeal intubation (28\%), continuous positive airway pressure (20\%), tracheostomy $(19 \%)$ and mandibular distraction osteogenesis $(5 \%)$. Tracheostomies were more prevalent in syndromic patients $(\mathrm{P}=0.03)$. Patients who underwent tracheostomy had a lower birth weight $(\mathrm{P}=0.03)$ compared with newborns with other interventions. Patients who underwent surgical interventions had longer intensive care unit stays $(\mathrm{P}<0.001)$. No intervention was associated with a statistically significant likelihood of requiring a subsequent intervention. Thirty percent of patients underwent polysomnography, with a higher proportion of these using continuous positive airway pressure $(n=15)(P<0.01)$.

CONCLUSIONS: In the present descriptive study, patients with syndromic PRS or low birth weight underwent early intervention, which included a tracheostomy. Objective measures of airway obstruction were underutilized. Decision making regarding evaluation and management of upper airway obstruction in this population remains clinician and resource dependent. Reporting data obtained from a large cohort of PRS patients is important to compare experiences and motivate future studies investigating this complex condition.

Key Words: Infant; Outcomes; Pierre Robin sequence; Polysomnography; Upper airway obstruction

Dierre Robin sequence (PRS) is a congenital anomaly characterized 1 by a triad of micrognathia, glossoptosis and a U-shaped cleft palate (1). Its incidence is approximately one in 8500 live births (2). It is hypothesized that mandibular hypoplasia before nine weeks' gestation displaces the tongue posteriorly and superiorly, preventing fusion of the palatal shelves. This produces a wide-ranging severity of upper airway obstruction.

Recurrent obstructive episodes put children at risk for chronic intermittent hypoxemia and hypoventilation. Persistent severe obstruction may lead to malnutrition, asphyxia, cor pulmonale and death. The trajectory of airway obstruction severity is unpredictable. Spontaneous improvement may occur by six months of age as the mandible lengthens and neuromuscular control of the tongue matures
Les interventions chirurgicales ou non chirurgicales pour soulager les obstructions des voies respiratoires supérieures chez les enfants ayant un syndrome de Pierre Robin

HISTORIQUE : Les nouveau-nés ayant un syndrome de Pierre Robin (SPR) présentent souvent une hypoxémie et une hypoventilation chroniques intermittentes associées à une obstruction des voies respiratoires supérieures. Puisque la gravité de l'obstruction est très hétérogène, la prise en charge est difficile. L'intervention optimale n'est pas établie.

OBJECTIF : Examiner la prévalence des interventions chirurgicales et non chirurgicales dans les cas de SPR de deux hôpitaux pour enfants. Examiner les caractéristiques des patients et les résultats.

MÉTHODOLOGIE : Les chercheurs ont effectué un examen rétrospectif des dossiers des 139 patients nés avec un SPR entre 2000 et 2010. Ils en ont extrait l'information démographique, le mode de prise en charge des voies respiratoires, les anomalies et syndromes connexes, les résultats de la polysomnographie, la durée du séjour en soins intensifs et du séjour hospitalier, les complications et les décès.

RÉSULTATS : Les interventions incluaient la position en décubitus ventral (seul [61 \%]), la fixation de la langue à la lèvre (45\%), l'intubation nasopharyngée (28\%), la ventilation en pression positive continue (20\%), la trachéotomie $(19 \%)$ et l'ostéogénèse mandibulaire par distraction (5\%). Les trachéotomies étaient plus courantes chez les patients syndromiques $(\mathrm{P}=0,03)$ et s'associaient à un plus petit poids à la naissance $(\mathrm{P}=0,03)$ que les autres interventions. Les patients qui ont subi des interventions chirurgicales ont séjourné plus longtemps en soins intensifs $(\mathrm{P}<0,001)$. Aucune intervention ne s'associait à une probabilité statistiquement significative de seconde intervention. Enfin, 30 \% des patients ont subi une polysomnographie, dont une plus forte proportion était également sous ventilation en pression positive continue $(\mathrm{n}=15)(\mathrm{P}<0,01)$.

CONCLUSIONS : Dans la présente étude descriptive, les patients ayant un SPR syndromique ou un petit poids de naissance ont subi une intervention précoce, y compris une trachéotomie. Les mesures objectives de l'obstruction des voies respiratoires étaient sous-utilisées. Au sein de cette population, la prise de décision relative à l'évaluation et à la prise en charge de l'obstruction des voies respiratoires supérieures dépend encore des ressources et du clinicien. Il s'impose de rendre compte des données tirées d'une vaste cohorte de patients ayant un SPR pour comparer les expériences et motiver les futures études sur ce problème complexe.

(3). Prognosis is influenced by whether PRS is isolated, part of an underlying syndrome or associated with other malformations (4).

Many PRS infants with upper airway obstruction are managed with simple measures such as repositioning (side lying, prone). Additional interventions include both nonsurgical (nasopharyngeal [NP] tube, continuous positive airway pressure [CPAP] via mask) as well as surgical (tongue-lip adhesion [TLA], mandibular distraction osteogenesis [MDO], tracheostomy) options. Sequential combinations of the modalities may be warranted. The timing of intervention is often dictated by the severity and frequency of airway obstruction, and the presence of comorbidities. Practitioners may differ with respect to the recommended treatment course for individual infants.

\footnotetext{
${ }^{1}$ Department of Pediatrics; ${ }^{2}$ University of Calgary, Calgary; ${ }^{3}$ Pediatrics, University of Alberta, Edmonton, Alberta

Correspondence: Dr Karen Kam, Section of Respiratory Medicine, Alberta Children's Hospital, 2888 Shaganappi Trail Northwest, Calgary,

Alberta T3B 6A8. Telephone 403-955-7503, fax 403-955-7059, e-mail karen.kam@albertahealthservices.ca
} 


\begin{tabular}{|c|c|}
\hline \multicolumn{2}{|l|}{ Type of PRS } \\
\hline Isolated PRS, n (\%) & $100(72)$ \\
\hline Syndromic PRS, or other chromosomal alteration, $\mathrm{n}(\%)$ & $39(28)$ \\
\hline Stickler syndrome & 8 \\
\hline Möebius syndrome & 6 \\
\hline Treacher-Collins syndrome & 5 \\
\hline Other chromosomal alteration (eg, 22q11, 4q31.3, 4q33) & 5 \\
\hline Goldenhaar syndrome & 4 \\
\hline Turner syndrome & 2 \\
\hline Bohring-Opitz syndrome & 1 \\
\hline Dubowitz syndrome & 1 \\
\hline Emanuel syndrome & 1 \\
\hline Facial femoral syndrome & 1 \\
\hline Freeman-Sheldon syndrome & 1 \\
\hline Smith-Lemli-Opitz syndrome & 1 \\
\hline Toriello-Carey syndrome & 1 \\
\hline Van der Woude syndrome & 1 \\
\hline Velocardiofacial syndrome & 1 \\
\hline
\end{tabular}

Data presented as $n$ unless otherwise indicated

Through population-based retrospective analysis, we investigated the prevalence of nonsurgical and surgical interventions to relieve upper airway obstruction in PRS infants at two children's hospitals in different metropolitan centres (within one publicly funded health care system). Characteristics of PRS infants, characteristics associated with certain interventions and outcomes were examined.

\section{Patient population}

\section{METHODS}

Medical charts were reviewed for patients with PRS born between 2000 and 2010 and assessed at two children's hospitals. Documentation of all three components of PRS defined by Robin (1) (micrognathia, glossoptosis, cleft palate) was required for inclusion. By including cleft palate, this encompassed all PRS patients who were assessed by a surgeon for future cleft palate repair. Although a referral from a health care provider is required for processing, both institutions have cleft lip and palate clinics that see all patients with a cleft palate residing in the areas serviced by the two hospitals. A total of 139 patients were identified between both sites.

\section{Retrospective review}

Data extracted include sex, gestational age, birth weight, feeding method (bottle feed, nasogastric tube, gastrostomy tube), associated anomalies and whether the sequence was isolated, or part of an underlying syndrome verified through genetic testing. If polysomnography (PSG) was performed, the timing and results were recorded. Airway management (repositioning, NP tube, CPAP, TLA, MDO, tracheostomy), time to intervention, duration of intensive care unit (ICU) stay, and duration of hospitalization after intervention were reviewed. If a patient underwent multiple interventions, the duration of ICU stay and hospitalization referred to the latest intervention performed. If patients received both nonsurgical and surgical interventions, they were categorized as receiving a surgical intervention for analysis. The duration of NP tube use, duration of CPAP use, time to TLA release, time to decannulation and age at cleft palate repair were extracted. Complications secondary to airway management, readmissions for complications and deaths in a hospital in the first three years of life were also recorded.

\section{Data analysis}

Descriptive statistics characterized the demographic information. Logistic regressions determined whether gestational age and birth weight were associated with patients undergoing a specific intervention. $\chi^{2}$ tests determined whether sex, isolated/syndromic PRS, presence of

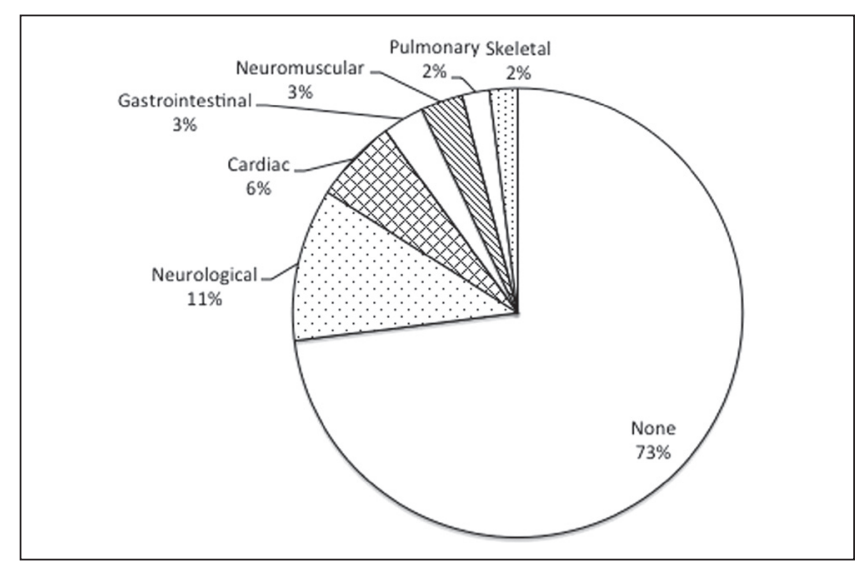

Figure 1) Associated anomalies in patients with isolated Pierre Robin sequence $(n=100)$

TABLE 2

Polysomnography results

\begin{tabular}{lcc}
\hline & \multicolumn{2}{c}{ Intervention } \\
& Pre & Post \\
\hline Oxygen saturation (nadir), \%, mean & 84 & 87 \\
End-tidal carbon dioxide, mmHg, mean & 43 & 41 \\
Apnea-hypopnea index, mean & 43.3 & 17.6 \\
Patients with no/mild/moderate/severe OSA, $\mathrm{n}$ & $0 / 1 / 3 / 14$ & $4 / 6 / 3 / 10$ \\
\hline OSA Obstructive sleep apnea & &
\end{tabular}

associated anomalies or PSG testing were associated with a particular intervention being performed. One-way ANOVAs determined whether surgical/nonsurgical interventions and individual interventions, were associated with ICU and hospitalization stays; $\mathrm{P}<0.05$ was considered to be statistically significant. Analyses were performed using SPSS version 19 (IBM Corporation, USA).

Approval for the present study was granted by the health research ethics board affiliated with both institutions.

\section{RESULTS}

Seventy-two (52\%) patients were male. The mean gestational age was 38.2 weeks (range 30 to 43 weeks), and mean birth weight was $3022 \mathrm{~g}$ (range $1375 \mathrm{~g}$ to $4485 \mathrm{~g}$ ). Seventy-two percent of patients had isolated PRS and $28 \%$ had an underlying syndrome or chromosomal deletion (Table 1). Figure 1 shows the prevalence of associated anomalies. The most common anomalies were neurological (11\%), which included seizures, microcephaly and agenesis of the corpus callosum. The most common cardiac anomalies (6\%) were atrial septal defects and ventricular septal defects.

Forty-two (30\%) patients underwent PSG, with similar proportions between hospitals. The mean age at initial PSG was 23 months (range five days to eight years). Of the 42 patients, 35 had isolated PRS and seven had syndromic PRS (P=0.06). Twelve percent of PSGs were performed before intervention. Fourteen (23\%) PSGs were performed with no subsequent intervention. Thirty patients had no or one intervention performed, and 12 patients had multiple interventions. Of the patients who underwent PSG, there was a higher proportion that used CPAP $(n=15) \quad(P<0.01)$. Of the patients with moderate/severe obstructive sleep apnea (OSA) on preintervention PSG, 11 subsequently used CPAP, five had a TLA and one patient had MDO. One patient with mild OSA was subsequently placed on CPAP. The mean apnea-hypopnea index (AHI) was higher in patients who underwent a subsequent intervention, compared with patients who did not undergo an intervention (40 versus four; $\mathrm{P}<0.01$ ). There were no differences in minimum oxygen saturation ( 81 versus $88 ; \mathrm{P}=0.06$ ) or mean end-tidal partial pressure of carbon dioxide between these groups (43 versus 42; $\mathrm{P}=0.42$ ). Results of pre- and postintervention PSG are summarized in Table 2. 


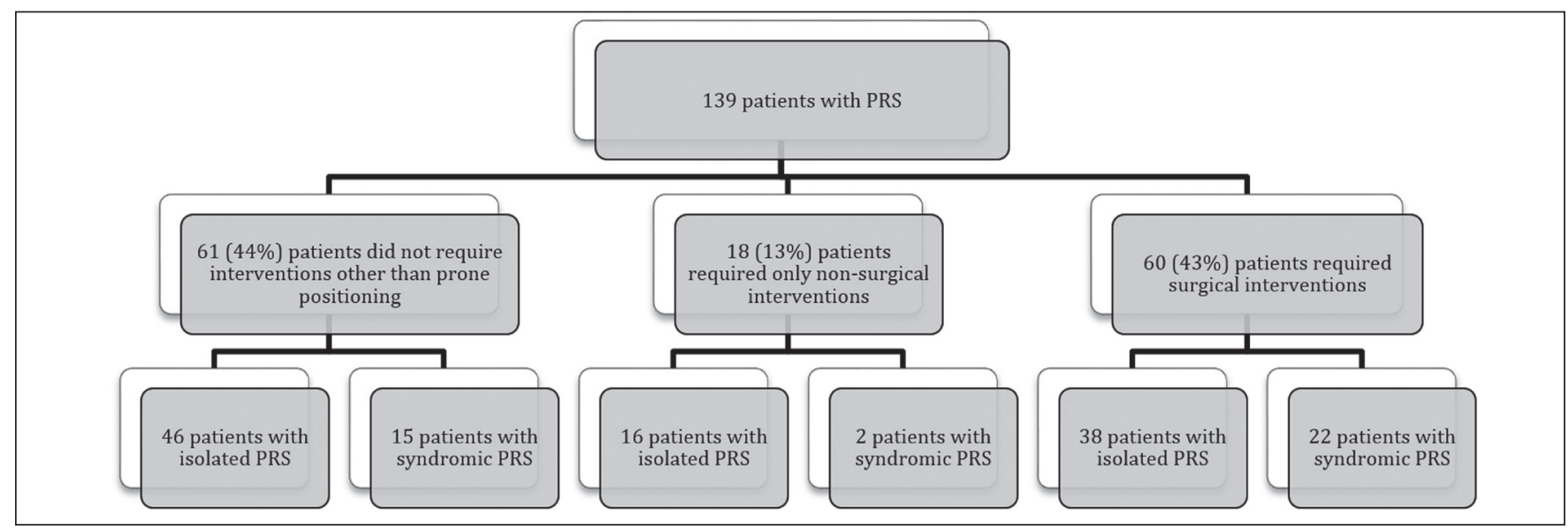

Figure 2) Interventions performed in patients with isolated or syndromic Pierre Robin sequence (PRS)

TABLE 3

Comparisons among treatment groups

\begin{tabular}{|c|c|c|c|c|c|c|}
\hline \multirow[b]{2}{*}{ Characteristic } & \multirow[b]{2}{*}{ No intervention } & \multicolumn{5}{|c|}{ Intervention } \\
\hline & & NP tube & CPAP & TLA & MDO & Tracheostomy \\
\hline n (hospital $1 \%$, hospital $2 \%$ ) & $61(49,51)$ & $28(61,39)^{*}$ & $20(45,55)$ & $45(5,95)^{*}$ & $5(80,20)$ & $19(26,74)$ \\
\hline Male/female, $n / n$ & $30 / 31$ & $9 / 19^{*}$ & $11 / 9$ & $24 / 21$ & $4 / 1$ & $11 / 8$ \\
\hline Isolated/syndromic Pierre Robin sequence, n/n & $46 / 15$ & $23 / 5$ & $14 / 6$ & $28 / 17$ & $4 / 1$ & $9 / 10^{\dagger}$ \\
\hline Birth weight, g & $3105 \pm 613$ & $3049 \pm 631$ & $3249 \pm 591$ & $3018 \pm 687$ & $3169 \pm 506$ & $2715 \pm 610^{\dagger}$ \\
\hline Time to intervention & - & $19 \pm 22$ days & $9 \pm 14$ months & $24 \pm 24$ days & $86 \pm 96$ days & $52 \pm 33$ days \\
\hline Intensive care unit stay, days & $0 \pm 0$ & $21 \pm 26$ & $16 \pm 23$ & $25 \pm 23$ & $29 \pm 35$ & $37 \pm 34^{*}$ \\
\hline Admission, days & $28 \pm 24$ & $58 \pm 46$ & $66 \pm 46$ & $56 \pm 53$ & $66 \pm 26$ & $138 \pm 76^{*}$ \\
\hline Length of intervention & - & $72 \pm 86$ days & $6 \pm 6$ months & $14 \pm 14$ months & - & $22 \pm 12$ months \\
\hline Age at cleft palate repair, months & $14 \pm 7$ & $14 \pm 3$ & $14 \pm 3$ & $12 \pm 4$ & $13 \pm 3$ & $15 \pm 4$ \\
\hline Patients who underwent polysomnography, $n$ & 14 & 11 & $15^{*}$ & 13 & 1 & 6 \\
\hline
\end{tabular}

Data presented as mean $\pm S D$ unless otherwise indicated. ${ }^{*} P<0.01 ;+P<0.05$. CPAP Continuous positive airway pressure; MDO Mandibular distraction osteogenesis; NP Nasopharyngeal; TLA Tongue-lip adhesion

The distribution of interventions is shown in Figure 2, and patient characteristics according to intervention are presented in Table 3. The number of patients that received each intervention includes those who received $>1$ intervention. Forty-seven (34\%) patients underwent one intervention, 24 (17\%) had two, six (4\%) had three and one (1\%) had four. The mean $( \pm$ SD) time to first intervention was $29 \pm 42$ days of life; the time to second intervention was $60 \pm 58$ days of life. For second interventions, common choices were CPAP $(n=9$ [31\%]) and tracheostomy $(n=8[28 \%])$. Of the 60 patients who underwent surgical interventions, 13 (22\%) underwent a previous nonsurgical intervention. Ten of the 13 patients had isolated PRS. Eighteen of the 54 patients (33\%) with isolated PRS who had undergone an intervention had $>1$ intervention. Twelve of the 24 (50\%) patients with syndromic PRS who underwent an intervention had $>1$ intervention $(\mathrm{P}=0.07)$. Of the three surgical interventions, TLA tended to be performed earlier (mean $24 \pm 24$ days), followed by tracheostomy (mean $52 \pm 33$ days) and MDO (mean $86 \pm 96$ days). No intervention was associated with a significant likelihood of needing a subsequent mode of management $(\mathrm{P}=0.12)$.

More female than male patients received an NP tube $(\mathrm{P}=0.03)$. The prevalence of tracheostomies was higher in patients with syndromic PRS $(P=0.03)$. Fifty percent of patients with syndromic PRS who underwent an intervention had a subsequent intervention, most often a tracheostomy. Regardless of whether the patient had isolated or syndromic PRS, those with a tracheostomy had significantly lower birth weights compared with children who underwent other interventions or no intervention $(P=0.03)$. Seven of the 19 patients retained their tracheostomy for the entire available chart data. All seven patients had either syndromic PRS or multiple systemic anomalies. No patient with a tracheostomy underwent PSG before intervention.
Gestational age was not associated with a specific intervention. Whether the patient had isolated or syndromic PRS did not impact the duration of NP intubation ( $\mathrm{P}=0.78)$, CPAP use $(\mathrm{P}=0.35)$, time to TLA release $(P=0.05)$ or time to decannulation $(P=0.36)$. Eightythree $(60 \%)$ patients had record of cleft palate closure. The mode of intervention did not affect the timing of cleft palate closure.

Ninety-seven $(70 \%)$ patients used a nasogastric and/or gastrostomy tube. Forty-one patients (30\%) had a gastrostomy tube during the airway management period, of which $49 \%$ had an underlying syndrome. Thirty-nine percent of children fed via gastrostomy tube underwent a tracheostomy.

Patients with only nonsurgical interventions had shorter mean ICU stays ( $4 \pm 11$ days, range one to 37 days) than patients who underwent surgical interventions $(25 \pm 25$ days, range two to 120 days) $(\mathrm{P}<0.001)$. Patients with a tracheostomy had significantly longer ICU admissions ( $37 \pm 24$ days, range 17 to 120 days) compared with other individual interventions $(\mathrm{P}<0.001)$. When infants with a tracheostomy were removed from the analysis, patients with surgical interventions (TLA, MDO) still had longer ICU admissions than patients with only nonsurgical interventions $(\mathrm{P}=0.02)$.

The mean hospitalization stay after intervention was $58 \pm 57$ days (range three to 301 days). There was no difference in mean admission length among patients without intervention ( $28 \pm 24$ days, range three to 75 days), patients with only nonsurgical interventions ( $35 \pm 32$ days, range six to 105 days) or patients with at least one surgical intervention (69 \pm 63 days, range 10 to 301 days) $(\mathrm{P}>0.05)$. Patients with a tracheostomy had significantly longer hospitalizations ( $138 \pm 76$ days, range 26 to 301 days) compared with other individual interventions $(\mathrm{P}<0.001)$.

Respiratory infections were the main reported complications. Increased oropharyngeal secretions were noted for patients with an NP 
tube. Two patients experienced TLA dehiscence by six months of age. Two patients with MDO experienced infections at the pin site and another developed osteomyelitis of the mandible. Other reasons for hospital readmission included management of aspiration pneumonitis and OSA. Most readmissions were for patients with a tracheostomy (51 readmissions for 19 patients by three years of age). Reasons for these readmissions included treatment of respiratory tract infections (35 of 51) and caregiver respite (nine of 51).

There were seven deaths in a hospital before three years of age. Six of the seven patients had either an underlying syndrome or multiple associated anomalies. Causes of mortality included septic shock $(n=2)$, liver failure secondary to sepsis $(n=1)$, postoperative complications from a gastrointestinal procedure $(n=1)$ and worsening lower airway obstruction secondary to pneumonia $(n=1)$. One patient with multiple cardiac lesions died of cardiac failure. Four patients underwent a tracheostomy; however, death was not directly related to a specific tracheostomy complication.

\section{DISCUSSION}

The present study supports the view that specific patient characteristics are associated with clinical decisions about the intervention to relieve upper airway obstruction in infants with PRS. Patients with an underlying syndrome or lower birth weight were more likely to undergo a tracheostomy. No particular intervention was shown to have a higher likelihood of proceeding to another intervention - in other words, was less successful than others. Also, outcomes were not significantly affected by the chosen intervention. The two institutions had different methods of managing airway obstruction in PRS patients: one hospital used more NP tubes while the other performed more TLAs. This suggests that clinician preference and experience, more than patient characteristics, was guiding management.

The reported prevalence of syndromic PRS ranges from 10\% to $60 \%(5-7)$. In our study, infants with syndromic PRS were more likely to undergo a surgical intervention to relieve airway obstruction. Particularly, they were more likely to undergo a tracheostomy than patients with isolated PRS, as previously reported (8). Syndromes may consist of craniofacial malformations, airway anomalies or difficulties with control of breathing that necessitates surgery to assist ventilation. An infant with underlying neurological deficits may also experience breathing difficulties. Although neurological anomalies were the most common associated anomalies in our study, the number was too low to compare with individual interventions. Handley et al (9) showed that infants with PRS and neurological impairment have a nearly fourfold increase in the odds of undergoing surgery (MDO, tracheostomy or prolonged intubation until death).

Studies report variable success with individual interventions $(5,10,11)$. In our study, $5 \%$ of patients were managed with an NP tube alone. Glynn et al (5) studied 69 infants with PRS, of whom 16 (23\%) had upper airway obstruction relieved with an NP tube alone. A case series by Abel et al (12) showed that $82 \%$ of infants were successfully managed with an NP airway alone. Complications are minimal, with increased oropharyngeal secretions most frequently reported. We cannot explain the higher prevalence of NP tube placement in females in our study.

Thirty-two percent of infants underwent TLA, in contrast with Bijnen et al (13), who found an improvement in breathing in $73 \%$ of patients who underwent TLA. In the same study, TLA had limited success in infants with multiple airway anomalies or issues with control of breathing. Patients with an underlying syndrome have been shown to be more likely to proceed to a tracheostomy (14). Complications of TLA include dehiscence, small chin abscess and unresolved airway obstruction $(13,15)$. Both NP tubes and TLA can be effective temporizing measures, perhaps avoiding more invasive procedures. They should be considered in infants with isolated PRS and no other levels of airway obstruction or risk for respiratory insufficiency.

$\mathrm{MDO}$ is an option to possibly avoid tracheostomy, or allow for early decannulation in patients with a tracheostomy. Genecov et al (16) used
MDO as their primary surgical intervention and avoided tracheostomy in $96 \%$ of patients who failed conservative treatment. Scott et al (17) noted better outcomes following MDO in patients with isolated PRS compared with patients with syndromic PRS and neurological deficits. Compared with tracheostomy, MDO offers a shorter ICU and hospital admission. Three of our five (60\%) MDO patients had an infection of the underlying bone or pin site, a known complication along with facial scarring, damage to the inferior alveolar nerve, anterior open bite deformity and permanent dentition loss (16-19). This high incidence of complications, albeit with a small sample, must be borne in mind by clinicians planning treatment regimens. MDO has been performed with increasing frequency over the past decade, although not in our two institutions (five procedures during the study period); clinician preference and experience is a factor in this decision.

The prevalence of tracheostomy in PRS patients is low. Case series report prevalences of up to $17 \%(7,20,21)$. In our study, infants had a lower birth weight (which has not been previously reported), and were more likely to have an underlying syndrome. Post-tracheostomy care requires a significantly longer ICU and hospital stay compared with other interventions. Patient condition, caregiver training and especially homecare availability and access to community resources, are reasons for an extended hospitalization (22). It is essential to monitor for potential complications such as sudden airway obstruction from mucous plugging or accidental decannulation, tracheal stenosis, airway infections and bleeding $(18,23)$. A tracheostomy could be the optimal intervention for patients with multiple levels of airway obstruction or lower airway disease. It should be considered in infants with an underlying syndrome to avoid complications of chronic hypoxemia and to maximize childhood development.

PSG was used infrequently in our patient population, perhaps due to unfamiliarity with the information it can provide, and concern about testing in an infant with a compromised airway. PSG was performed late (mean 23 months), with few performed before initial intervention. This could explain why CPAP use was lower than previously reported because titration is limited without objective measures of airway obstruction. Anderson et al (24) reports a higher percentage of infants underging PSG before intervention (39\%). In a study by Daniel et al (25), all PRS infants admitted to the neonatal unit underwent PSG, which demonstrated OSA in all patients. Bull et al (26) showed that six of seven children with PRS and multiple congenital anomalies had more significant desaturations seen on PSG compared with children with isolated PRS (26). Significant hypoxia and apnea may be present without clinically apparent obstructive symptoms (26,27). Although our numbers were small, results suggest that the AHI is important to consider when deciding whether an intervention is warranted. Given the noninvasive nature of PSG, it should be considered as a tool to guide decisions and measure the effectiveness of interventions. Outcome markers, such as AHI, would be valuable for further studies of interventions in PRS infants.

Infants with PRS may experience feeding difficulties. The proportion of infants requiring a feeding intervention (70\%) is consistent with previous reports $(4,5,10)$. Gastrostomy tube usage has been reported to be higher in PRS patients with congenital anomalies (4). It is suggested that delayed weight gain is correlated with the degree of airway obstruction (28). Slow growth may be an indicator for prompt intervention and is a topic for further study.

The present retrospective chart review studied all infants with PRS who were managed in the province's children's hospitals in the given time period. We recognize that the assessment and comparison of interventions in complex, rapidly evolving medical conditions is fraught with problems. A randomized trial, considered to be the best evidence, is difficult to design and execute in a heterogeneous population because predetermined exclusion criteria may not mimic real-life situations. There is likely to be recruitment and retention bias because study participants, caregivers and decision makers frequently modify their decisions when they know they are being observed. As examples of the dilemma, studies have compared one individual intervention 
with another or compared with conservative management (11). There are few studies investigating a range of interventions. It is not clear how best to study the relative roles of repositioning, nonsurgical interventions and/or surgical interventions in a larger cohort of PRS infants.

We also recognize the limitations to our study design. A chart review is subject to missing data and there was no standardization in the way data were recorded in the health chart. Institutional differences in the threshold and preference for certain surgical procedures are confounding variables. Similarly, MDO was not performed in the hospitals until later in the study period. The level of hypoxemia is uncertain because oxygen saturation was not consistently recorded in the charts. Many variables were examined, which limits drawing conclusions in the setting of multiple comparisons.

The evidence presented enriches our understanding of the population, and can be used in the development of a prospective study with a uniform protocol for investigations, patient interventions and data collection. The protocol must involve committed clinicians and also allow for urgent interventions if an infant deteriorates without excluding them from the trial. The next step, we believe, is to present the data from our study to a group of clinicians and research methodologists in several centres to begin planning a formal prospective study.

The spectrum of presenting features, upper airway obstruction and its unpredictable progression makes the management of PRS patients unique. Newborns with an underlying syndrome and low birth weight

\section{REFERENCES}

1. Robin P. Glossoptosis due to atresia and hypotrophy of the mandible. Am J Dis Children 1934;48:541-7.

2. Bush PG, Williams AJ. Incidence of the Robin anomalad (Pierre Robin syndrome). Br J Plast Surg 1983;36:434-7.

3. Silke W, Sukh SR, Andy JT, Peter G, Rona S. Management of infants with Pierre Robin sequence. Cleft Palate Craniofac J 2003;40:180-5.

4. Smith MC, Senders CW. Prognosis of airway obstruction and feeding difficulty in the Robin sequence. Int J Pediatr Otorhinolaryngol 2006;70:319-24.

5. Glynn F, Fitzgerald D, Earley MJ, Rowley H. Pierre Robin sequence: An institutional experience in the multidisciplinary management of airway, feeding and serous otitis media challenges. Int J Pediatr Otorhinolaryngol 2011;75:1152-5.

6. Izumi K, Konczal LL, Mitchell AL, Jones MC. Underlying genetic diagnosis of Pierre Robin sequence: Retrospective chart review at two children's hospitals and a systematic literature review. J Pediatr 2012;160:645,650.e2.

7. Butow KW, Hoogendijk CF, Zwahlen RA. Pierre Robin sequence: Appearances and 25 years of experience with an innovative treatment protocol. J Pediatr Surg 2009;44:2112-8.

8. Schaefer RB, Stadler JA III, Gosain AK. To distract or not to distract: An algorithm for airway management in isolated Pierre Robin sequence. Plast Reconstr Surg 2004;113:1113-25.

9. Handley SC, Mader NS, Sidman JD, Scott AR. Predicting surgical intervention for airway obstruction in micrognathic infants. Otolaryngol Head Neck Surg 2013;148:847-51.

10. Evans AK, Rahbar R, Rogers GF, Mulliken JB, Volk MS. Robin sequence: A retrospective review of 115 patients. Int J Pediatr Otorhinolaryngol 2006;70:973-80.

11. Al-Samkari HT, Kane AA, Molter DW, Vachharajani A. Neonatal outcomes of Pierre Robin sequence: An institutional experience. Clin Pediatr (Phila) 2010;49:1117-22.

12. Abel F, Bajaj Y, Wyatt M, Wallis C. The successful use of the nasopharyngeal airway in Pierre Robin sequence: An 11-year experience. Arch Dis Child 2012;97:331-4.

13. Bijnen CL, Don Griot PJ, Mulder WJ, Haumann TJ, Van Hagen AJ. Tongue-lip adhesion in the treatment of Pierre Robin sequence. J Craniofac Surg 2009;20:315-20.

14. Kirschner RE, Low DW, Randall P, et al. Surgical airway management in Pierre Robin sequence: Is there a role for tongue-lip adhesion? Cleft Palate Craniofac J 2003;40:13-8.

15. Myer CM III, Reed JM, Cotton RT, Willging JP, Shott SR. Airway management in Pierre Robin sequence. Otolaryngol Head Neck Surg 1998;118:630-5. may be considered for tracheostomy. Although underutilized in this study, PSG may be an invaluable tool to assess the need and timing for intervention. This warrants further study. Approach to decision making regarding evaluation and management of upper airway obstruction in this population remains clinician and resource dependent. Further multicentre studies of interventions in PRS patients are important to standardize management and share best practices in this heterogeneous population. These studies should include long-term follow-up to explore the implications of early treatment on long-term health outcomes.

ACKNOWLEDGEMENTS: Karen Kam - contributions to conception and design, acquisition of data, data interpretation, drafting of submitted manuscript, final approval of article. Meghan McKay - contributions to data analysis, drafting of submitted manuscript, final approval of article. Joanna MacLean - contributions to conception, drafting of submitted manuscript, final approval of article. Manisha Witmans - contributions to conception, drafting of submitted manuscript, approval of article. Sheldon Spier - contributions to conception, drafting of submitted manuscript, approval of article. Ian Mitchell - contributions to conception and design, data interpretation, drafting of submitted manuscript, final approval of article.

DISCLOSURES: The authors have no financial disclosures or conflicts of interest to declare.

16. Genecov DG, Barcelo CR, Steinberg D, Trone T, Sperry E. Clinical experience with the application of distraction osteogenesis for airway obstruction. J Craniofac Surg 2009;(20 Suppl 2):1817-21.

17. Scott AR, Tibesar RJ, Lander TA, Sampson DE, Sidman JD. Mandibular distraction osteogenesis in infants younger than 3 months. Arch Facial Plast Surg 2011;13:173-9.

18. Scott AR, Tibesar RJ, Sidman JD. Pierre Robin sequence: Evaluation, management, indications for surgery, and pitfalls. Otolaryngol Clin North Am 2012;45:695,710, ix.

19. Tibesar RJ, Scott AR, McNamara C, Sampson D, Lander TA, Sidman JD. Distraction osteogenesis of the mandible for airway obstruction in children: Long-term results. Otolaryngol Head Neck Surg 2010;143:90-6.

20. Benjamin B, Walker P. Management of airway obstruction in the Pierre Robin sequence. Int J Pediatr Otorhinolaryngol 1991;22:29-37.

21. Sher AE, Shprintzen RJ, Thorpy MJ. Endoscopic observations of obstructive sleep apnea in children with anomalous upper airways: Predictive and therapeutic value. Int J Pediatr Otorhinolaryngol 1986;11:135-46.

22. Al-Samri M, Mitchell I, Drummond DS, Bjornson C. Tracheostomy in children: A population-based experience over 17 years. Pediatr Pulmonol 2010;45:487-93.

23. Pereira KD, MacGregor AR, Mitchell RB. Complications of neonatal tracheostomy: A 5-year review. Otolaryngol Head Neck Surg 2004;131:810-3.

24. Anderson IC, Sedaghat AR, McGinley BM, Redett RJ, Boss EF, Ishman SL. Prevalence and severity of obstructive sleep apnea and snoring in infants with Pierre Robin sequence. Cleft Palate Craniofac J 2011;48:614-8.

25. Daniel M, Bailey S, Walker K, et al. Airway, feeding and growth in infants with Robin sequence and sleep apnoea. Int J Pediatr Otorhinolaryngol 2013;77:499-503.

26. Bull MJ, Givan DC, Sadove AM, Bixler D, Hearn D. Improved outcome in Pierre Robin sequence: Effect of multidisciplinary evaluation and management. Pediatrics 1990;86:294-301.

27. Singer L, Sidoti EJ. Pediatric management of Robin sequence. Cleft Palate Craniofac J 1992;29:220-3.

28. Stubenitsky BM, Taylor HO, Peters D, Kelly C, Harkness M, Forrest C. Predictive value of weight gain and airway obstruction in isolated Robin sequence. Cleft Palate Craniofac J 2010;47:378-81. 


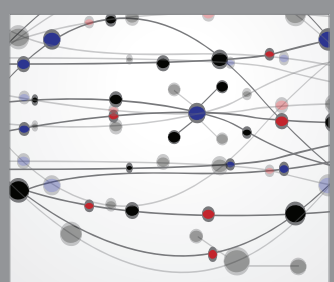

The Scientific World Journal
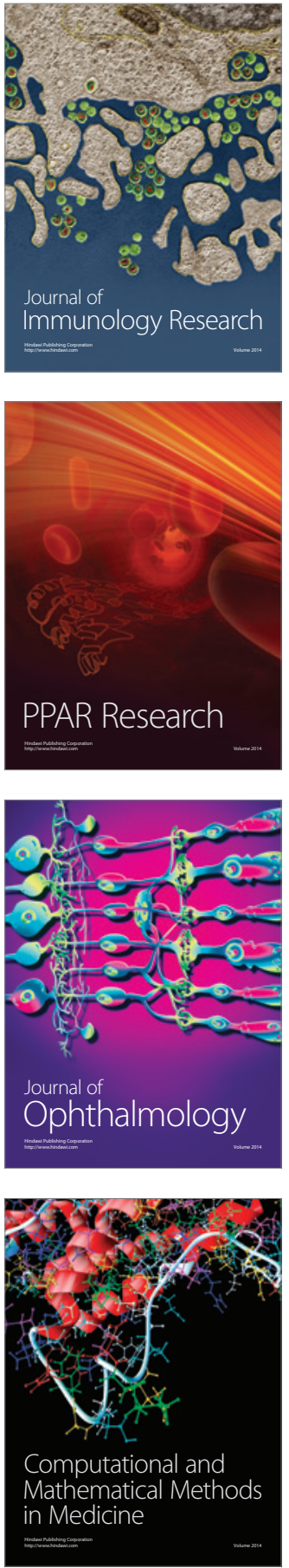

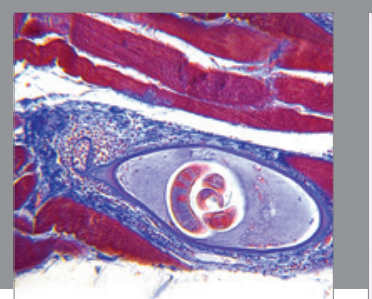

Gastroenterology Research and Practice

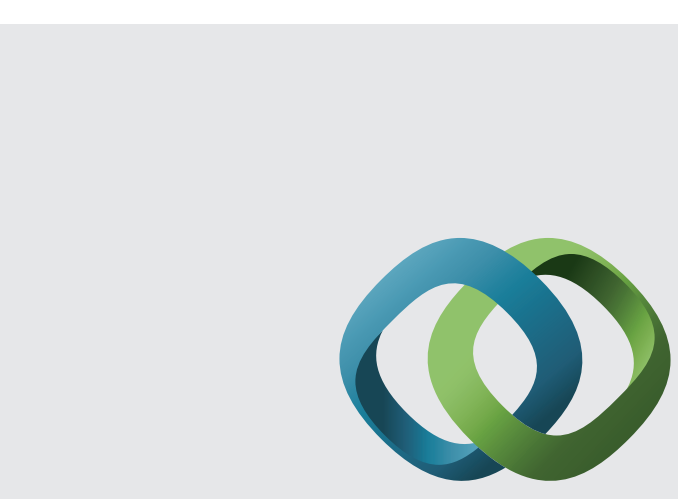

\section{Hindawi}

Submit your manuscripts at

http://www.hindawi.com
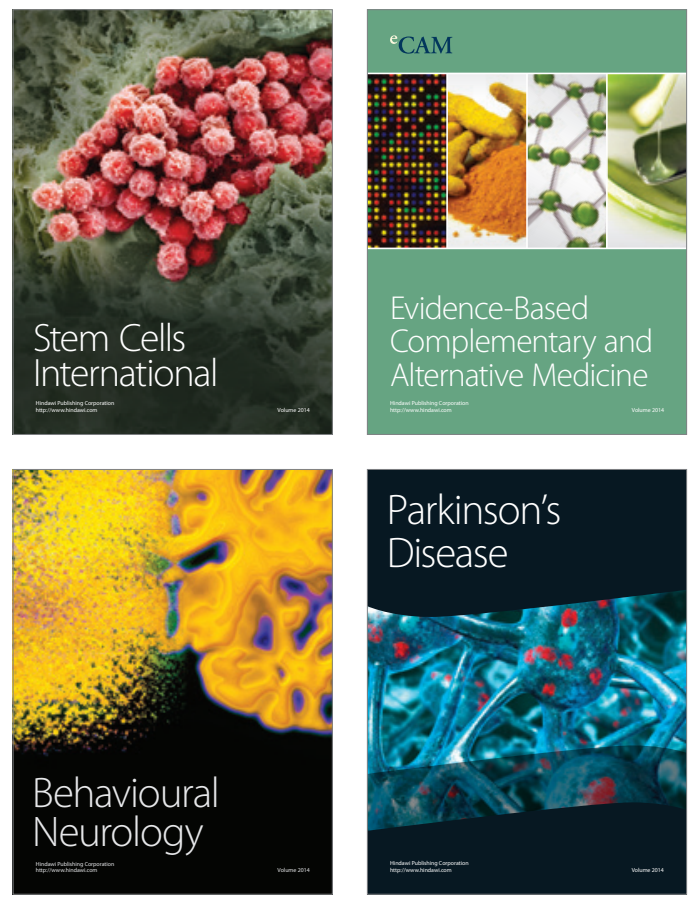
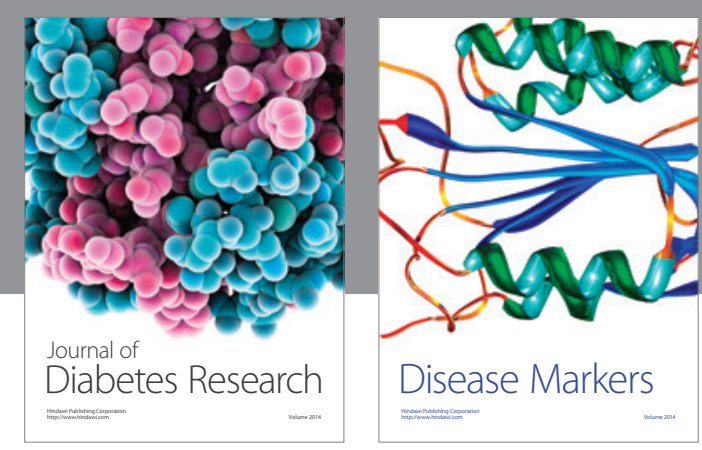

Disease Markers
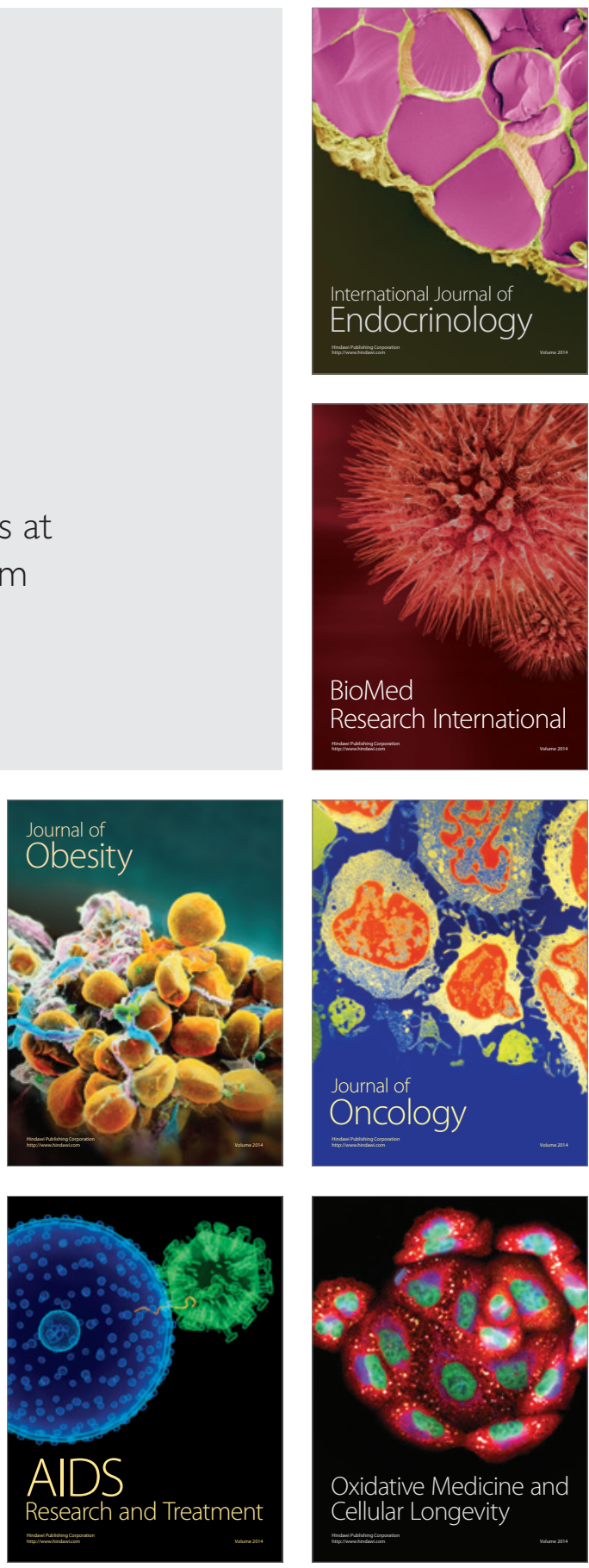